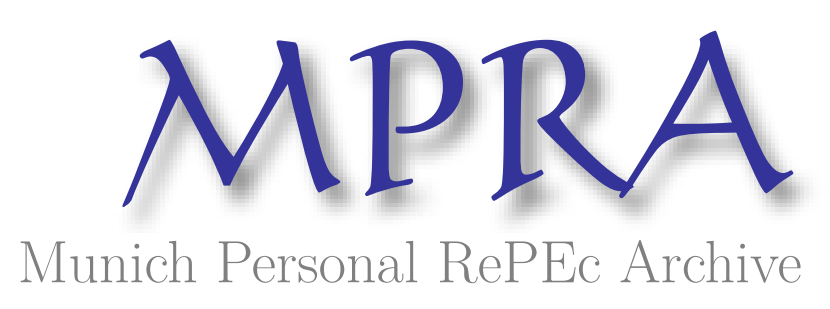

\title{
On simple contracts, renegotiation under asymmetric information, and the hold-up problem
}

Schmitz, Patrick W.

2002

Online at https://mpra.ub.uni-muenchen.de/12530/

MPRA Paper No. 12530, posted 06 Jan 2009 06:16 UTC 


\title{
On simple contracts, renegotiation under asymmetric information, and the hold-up problem
}

\author{
Patrick W. Schmitz* \\ University of Bonn, Adenauerallee 24-42, D-53113 Bonn, Germany
}

January 2002

\begin{abstract}
In this article it is demonstrated that voluntary bargaining over a collective decision under asymmetric information may well lead to ex post efficiency if the default decision is non-trivial. It is argued that the default decision may be interpreted as a 'simple' contract that the parties have written ex ante. This result is used in order to show that simple unconditional contracts which are renegotiated may allow the hold-up problem to be solved, even if the parties' valuations are private information.
\end{abstract}

JEL classification: D23; D82; L14

Keywords: Contract theory; Private information; Hold-up problem

* This is the working paper version of the following article:

Schmitz, P.W., "Simple contracts, renegotiation under asymmetric information, and the hold-up problem," European Economic Review, Vol. 46 (1), 2002, 169-188.

I would like to thank Yeon-Koo Che, Anke Kessler, Georg Nöldeke, Stefan Reichelstein, Stephanie Rosenkranz, Dirk Sliwka, and in particular Urs Schweizer for useful discussions. 


\section{Introduction}

This article considers a variant of a standard mechanism design problem. There are $n$ risk-neutral agents who have to make a collective decision $q \in$ $[0,1]$. The decision $q=1$ is ex post efficient whenever the sum of the agents' valuations for an affirmative decision is positive, whereas $q=0$ is ex post efficient otherwise. The agents posses private information on their independently distributed valuations. It is by now well known that ex post efficiency can be achieved in such a problem with quasi-linear utilities, if the parties can write a comprehensive contract ex ante; i.e., before they privately learn their types (see D'Aspremont and Gérard-Varet, 1979, and Arrow, 1979). In this paper it is assumed instead that ex ante the parties can only write a simple ('incomplete') contract which merely consists of an unconditional trade level $q_{0} \in[0,1] .^{1}$ Can voluntary bargaining that starts after the parties have learned their valuations lead to ex post efficiency, given that the ex ante contract just specifies a default decision $q_{0}$ ?

The impossibility result of Myerson and Satterthwaite (1983) says that given a non-trivial decision problem, in the case $n=2$ ex post efficiency cannot be achieved if $q_{0}=0$ (which corresponds to no ex ante contract). For $n>2$, the impossibility result has been further strengthened by Güth and Hellwig (1986). ${ }^{2}$ In contrast, here it is argued that ex post efficiency may be achieved if $q_{0} \neq 0$.

This paper is motivated by a major problem in contract theory. While optimal complete contracts are often quite complicated, real world contracts seem to be rather simple. ${ }^{3}$ One possible explanation is the fact that even

\footnotetext{
${ }^{1}$ In addition, the contract may specify a lump sum up-front payment.

${ }^{2}$ See also Rob (1989) and Mailath and Postlewaite (1990).

${ }^{3}$ Cf. Hart and Holmström (1987) and Hart (1995).
} 
though simple contracts may often not be flexible enough to induce the first best directly, they may be efficient if they are renegotiated in a certain way (cf. Huberman and Kahn, 1988). In particular, several recent papers have shown that while the well-known hold-up problem can often be solved by sophisticated contracts (see Rogerson, 1992), it may also be solved by simple contracts that just specify a threatpoint for future negotiations, given that the parties are symmetrically informed (cf. Aghion, Dewatripont and Rey, 1990 and 1994, Chung, 1991, Nöldeke and Schmidt, 1995 and 1998, Edlin, 1996, and Edlin and Reichelstein, 1996). ${ }^{4}$ This paper attempts to make a first exploratory step directed at a generalization of these insights to the case of private information.

The paper is organized as follows. The first result in Section 2 characterizes decision rules that can be implemented if the default decision is exogenously given by some value $q_{0} \in[0,1]$. The second result shows that in the case of identically distributed valuations, there is an easily interpreted default decision $q_{0}$, such that ex post efficiency can be achieved for any number $n$ of agents. The third result shows that in the setting of Myerson and Satterthwaite (1983), ex post efficiency is always achievable if the default decision is chosen appropriately. In Section 3 it is argued that this insight can be folded back into a trading problem with ex ante investments to achieve the first best in a hold-up problem with private information. The results are further discussed in Section 4. All proofs have been relegated to the appendix.

\footnotetext{
${ }^{4}$ This positive view of renegotiation has to be distinguished from the 'renegotiationproofness' concept in traditional complete contract theory, where the class of contracts that can initially be written is not restricted. There, the fact that parties cannot rule out renegotiation can only be harmful, since it imposes additional constraints.
} 


\section{Voluntary bargaining under asymmetric in- formation}

Consider $n \geq 2$ risk-neutral agents indexed by $i \in\{1, \ldots, n\}$. A collective decision $q \in[0,1]$ has to be reached. If agent $i$ receives $t_{i}$ dollars, his or her utility is given by $v_{i} q+t_{i}$, where $v_{i} \in\left[a_{i}, b_{i}\right]$ denotes agent $i$ 's willingness-topay. The agents' valuations $v_{i}$ are modelled as independent random variables. Agent $i$ 's valuation is distributed according to the commonly known distribution function $F_{i}\left(v_{i}\right)$, which is continuous and strictly increasing on $\left[a_{i}, b_{i}\right]$. Let the corresponding density function be denoted by $f_{i}\left(v_{i}\right)$. Assume that the default decision is given by $q_{0} \in[0,1]$; i.e., there is an exogenously given 'constitution' (or a simple prior contract) which says that if the $n$ agents do not reach a different agreement, the decision will be $q_{0}$. Bargaining is assumed to be voluntary, such that an agreement to choose $q \neq q_{0}$ can only be reached unanimously.

According to the revelation principle (cf. Myerson, 1982), any Bayesian equilibrium outcome of any conceivable bargaining game among the $n$ agents can also be obtained as the equilibrium outcome of a direct mechanism in which the agents report their types truthfully. Let $\tilde{v}$ denote the vector of reports, $\left(\tilde{v}_{1}, \ldots, \tilde{v}_{n}\right)$. A direct mechanism, $[q(\tilde{v}), t(\tilde{v})]$, consists of a decision rule $q: \Pi_{i=1}^{n}\left[a_{i}, b_{i}\right] \rightarrow[0,1]$ and a transfer rule $t=\left\{t_{i}\right\}_{i=1}^{n}$, where $t_{i}: \Pi_{i=1}^{n}\left[a_{i}, b_{i}\right] \rightarrow \mathbb{R}$. It is assumed that a mechanism must satisfy the budget constraint $\sum_{i=1}^{n} t_{i}(\tilde{v})=0 \forall \tilde{v}$. The parties can accept or reject the mechanism. If at least one party does not accept the mechanism, the default decision $q_{0}$ is implemented. Otherwise the parties announce their valuations and then the decision and transfer payments are determined by the mechanism.

Let $Q_{i}\left(\tilde{v}_{i}\right)=E_{-i}\left[q\left(\tilde{v}_{i}, v_{-i}\right)\right]$ denote the expected decision and let $T_{i}\left(\tilde{v}_{i}\right)=$ 
$E_{-i}\left[t_{i}\left(\tilde{v}_{i}, v_{-i}\right)\right]$ denote agent $i$ 's expected transfer, given that agent $i$ reports $\tilde{v}_{i}$ and assuming that the other agents tell the truth. ${ }^{5}$ If agent $i$ tells the truth, his or her interim expected utility is given by $U_{i}\left(v_{i}\right)=v_{i} Q_{i}\left(v_{i}\right)+T_{i}\left(v_{i}\right)$. For a mechanism to induce truthful reporting, it must be incentive compatible:

Definition 1 A mechanism $[q(v), t(v)]$ is called Bayesian incentive compatible if and only if $\forall i, \forall v_{i}, \forall \tilde{v}_{i}$ :

$$
U_{i}\left(v_{i}\right) \geq v_{i} Q_{i}\left(\tilde{v}_{i}\right)+T_{i}\left(\tilde{v}_{i}\right) .
$$

Given that the other agents tell the truth, condition (1) guarantees that it is rational for agent $i$ to also tell the truth. The following lemma, which is a standard application of mechanism design techniques, provides a very convenient characterization of incentive compatible mechanisms.

Lemma 1 A mechanism $[q(v), t(v)]$ is Bayesian incentive compatible if and only if $Q_{i}\left(v_{i}\right)$ is non-decreasing for all $i$ and $\forall i, \forall v_{i}, \forall \tilde{v}_{i}$ :

$$
U_{i}\left(v_{i}\right)=U_{i}\left(\tilde{v}_{i}\right)+\int_{\tilde{v}_{i}}^{v_{i}} Q_{i}\left(\check{v}_{i}\right) d \check{v}_{i}
$$

In particular, the lemma says that in a Bayesian incentive compatible mechanism the interim expected utility $U_{i}\left(v_{i}\right)$ of agent $i$ is uniquely determined (up to an integration constant) by the decision rule. Bargaining is voluntary, hence each agent can refuse to participate in the mechanism. Since non-participation of an agent leads to the decision $q_{0}$ which can also be prescribed by the mechanism itself, there is no loss of generality by restricting attention to mechanisms in which all types participate. ${ }^{6}$

\footnotetext{
${ }^{5}$ As usual, $\left(\tilde{v}_{i}, v_{-i}\right)$ denotes the vector $\left(v_{1}, \ldots, v_{i-1}, \tilde{v}_{i}, v_{i+1}, \ldots, v_{n}\right)$ and $E_{-i}$ is the expectation operator with respect to $v_{-i}=\left(v_{1}, \ldots, v_{i-1}, v_{i+1}, \ldots, v_{n}\right)$.

${ }^{6}$ Note that in general this would not necessarily be the case if (instead of an ex ante fixed $q_{0}$ ) one of the parties were given the right to choose $q_{0}$ ex post (cf. Klibanoff and Morduch, 1995).
} 
Definition 2 A mechanism $[q(v), t(v)]$ is called interim individually rational if and only if $\forall i, \forall v_{i}$ :

$$
U_{i}\left(v_{i}\right) \geq q_{0} v_{i}
$$

The case that has received most attention in the literature is given by $q_{0}=0$. In this case, participation of the lowest possible type (i.e., $U_{i}\left(a_{i}\right) \geq 0$ $\forall i)$ is necessary and sufficient for $(2)$. If $q_{0}=0$, the type $a_{i}$ is the type that is worst-off from participating in a Bayesian incentive compatible mechanism, because $U_{i}\left(v_{i}\right)$ is a non-decreasing function (see Lemma 1). The following lemma generalizes this idea to the present setting where $q_{0} \neq 0$ is possible.

Lemma 2 A Bayesian incentive compatible mechanism $[q(v), t(v)]$ is interim individually rational if and only if $\forall i$

$$
U_{i}\left(v_{i}^{0}\right) \geq q_{0} v_{i}^{0}
$$

where agent $i$ 's worst-off type $v_{i}^{0}$ is characterized by

$$
v_{i}^{0}= \begin{cases}a_{i} & \text { if } q_{0} \leq Q_{i}\left(a_{i}\right) \\ \mathfrak{w}\left(q_{0}\right) & \text { if } Q_{i}\left(a_{i}\right)<q_{0} \leq Q_{i}\left(b_{i}\right) \\ b_{i} & \text { if } q_{0}>Q_{i}\left(b_{i}\right),\end{cases}
$$

where $\mathfrak{w}\left(q_{0}\right)$ satisfies $q_{0}=Q_{i}\left(\mathfrak{w}\left(q_{0}\right)\right)$.

Note that with $q_{0} \neq 0$, the lowest possible valuation does no longer need to be the worst-off type. For instance, if $q_{0}=1$, an agent with the highest possible valuation can lose the most from participating in the mechanism. The following proposition provides a necessary and sufficient condition for a mechanism to be incentive compatible and individually rational, provided the exogenous default decision is given by $q_{0} \in[0,1]$. 
Proposition 1 Let $q(v)$ be a decision rule such that $Q_{i}\left(v_{i}\right)$ is non-decreasing for all $i$. There exists a transfer rule $t(v)$ such that $[q(v), t(v)]$ is a Bayesian incentive compatible and interim individually rational mechanism if and only if

$$
\begin{aligned}
& \sum_{i=1}^{n}\left(\int_{v_{i}^{0}}^{b_{i}}\left(v_{i}-\frac{1-F_{i}\left(v_{i}\right)}{f_{i}\left(v_{i}\right)}\right) Q_{i}\left(v_{i}\right) f_{i}\left(v_{i}\right) d v_{i}\right. \\
& \left.+\int_{a_{i}}^{v_{i}^{0}}\left(v_{i}+\frac{F_{i}\left(v_{i}\right)}{f_{i}\left(v_{i}\right)}\right) Q_{i}\left(v_{i}\right) f_{i}\left(v_{i}\right) d v_{i}\right) \geq \sum_{i=1}^{n} q_{0} v_{i}^{0} .
\end{aligned}
$$

It may be useful to take a closer look at condition (3). The term on the left hand side is the sum of all agents' interim expected utilities, given that they participate in a Bayesian incentive compatible mechanism and provided they are of their worst-off types. Consider the case $q_{0}=0$. Then $v_{i}^{0}=a_{i}$, and condition (3) becomes ${ }^{7}$

$$
\sum_{i=1}^{n} E\left[\left(v_{i}-\frac{1-F_{i}\left(v_{i}\right)}{f_{i}\left(v_{i}\right)}\right) q(v)\right] \geq 0
$$

If there were no private information, any $q(v)$ such that $\sum_{i=1}^{n} v_{i} q(v) \geq 0$ could obviously be part of an interim individually rational mechanism. In the presence of private information, this condition has to be expressed in expected values and modified such that the true valuation $v_{i}$ is replaced by the term $v_{i}-\frac{1-F_{i}\left(v_{i}\right)}{f_{i}\left(v_{i}\right)}$, which is known as agent $i$ 's 'virtual valuation'. 8 It reflects the distortion introduced due to the fact that the agents must be induced to report their valuations honestly. If the mechanism failed to account for this incentive effect, the agents were tempted to understate their valuations (in

\footnotetext{
${ }^{7}$ This condition is known from Güth and Hellwig (1986) and Mailath and Postlewaite

${ }^{8}$ The 'virtual valuation' (cf. Myerson, 1981) appears in many related models where agents have private information about their willingness-to-pay. See Bulow and Roberts (1989) for an interesting economic interpretation of 'virtual valuations' and 'virtual costs'.
} (1990). 
other words, bias their reports towards the worst-off type, i.e., the lowest possible valuation, in order to decrease their payments). Analogously, in models in which agents have private information about their costs,${ }^{9}$ the 'virtual costs' term $v_{i}+\frac{F_{i}\left(v_{i}\right)}{f_{i}\left(v_{i}\right)}$ appears (where the true costs are given by $v_{i}$ ), reflecting the fact that one must induce agents not to overstate their costs (the agents want to pretend to be of the worst-off type, i.e., have the highest possible costs, in order to receive a large compensation). In the present model, the incentives to understate and to overstate may be balanced, since with a default decision $0<q_{0}<1$, the worst-off type can occur at an intermediate valuation. ${ }^{10}$

It is worth noting that the proposition above applies to any decision rule $q$ such that $Q_{i}$ is increasing for all $i$. There is one such decision rule which is of particular interest, namely the rule which maximizes total surplus. ${ }^{11}$

Definition 3 The ex post efficient decision rule $q^{*}(v)$ is given by

$$
q^{*}(v)= \begin{cases}1 & \text { if } \sum_{i=1}^{n} v_{i} \geq 0 \\ 0 & \text { otherwise. }\end{cases}
$$

Hence, ex post efficiency can be achieved whenever (3) holds, where $Q_{i}\left(v_{i}\right)=E_{-i}\left(q^{*}(v)\right)$.

\footnotetext{
${ }^{9}$ For example, see Rob (1989).

${ }^{10}$ Hence, there may be 'countervailing incentives' in the sense of Lewis and Sappington (1989) and Maggi and Rodríguez-Clare (1995).

${ }^{11}$ Of course, the ex post efficient decision rule is not the only one which has received attention in the literature. For example, Rob (1989) analyzes the problem of a firm that must decide whether or not to build a polluting plant. The affected residents are entitled to maintain the status quo $\left(q_{0}=0\right.$; i.e., 'clean air'). He assumes that the firm has all bargaining power and hence considers the decision rule which maximizes the firm's profit. Mailath and Postlewaite (1990) consider a public good problem and analyze the decision rule which maximizes the probability of provision. Proposition 1 can be applied to any such decision rule in order to check how robust the results are when the default decision is different from zero.
} 
While Myerson and Satterthwaite (1983) showed that private information may render ex post efficiency unattainable, Rob (1989) and Mailath and Postlewaite (1990) suggest that in the case of many agents private information even leads to complete inertia; i.e., a move away from the status quo cannot be achieved without coercion. However, these negative results crucially depend on the implicit assumption that the default decision is given by $q_{0}=0$. If $q_{0}$ lies in the interior of the unit interval, there are non-trivial situations in which even ex post efficiency can be achieved for any number $n$ of agents, as the following proposition illustrates.

Proposition 2 Consider the case $F_{i}=F \forall i$ and let the default decision be given by $q_{0}=\operatorname{Pr}\left\{\sum_{j \neq i} v_{j} \geq 0\right\}$. Then there exists a Bayesian incentive compatible, interim individually rational and ex post efficient mechanism.

Note that the default decision $q_{0}$ specified in the proposition has a straightforward interpretation. The default decision is such that if agent $i$ does not participate, then he or she expects the decision to be what is efficient for the $n-1$ other agents; i.e., when agent $i$ 's preferences are simply disregarded. In this case, each agent is better off when he or she participates and in this way ex post efficiency can be achieved.

Proposition 2 is closely related to the efficiency result of Cramton, Gibbons, and Klemperer (1987). They also consider $n$ agents with identically distributed valuations. However, their analysis concerns the dissolution of partnerships. Specifically, they show that ex post efficiency can be achieved if initially every agent holds a certain share of a good, when it is ex post efficient that only one agent possesses $100 \%$ of the good (namely, the agent with the highest valuation). Therefore, while they consider a private good setting, Proposition 2 illustrates that a result in a similar spirit can also be 
obtained in a public good setting, in which every agent must 'consume' the same amount $q \cdot{ }^{12}$

In Section 3 a possible interpretation of endogenously chosen default decisions $q_{0}$ (namely, simple prior contracts) will be discussed in the framework of the hold-up problem. The following result will be particularly important for this discussion. Consider the bilateral trading problem of Myerson and Satterthwaite (1983); i.e. there is a buyer who is interested in a good that can be provided by a seller. Formally, let $v_{1}$ denote the buyer's valuation and $-v_{2}$ the seller's costs. The following proposition says that one can always find a level of trade $q_{0}$ such that ex post efficiency can be achieved.

Proposition 3 It is always possible to find a default decision $q_{0}$ in the bilateral trading problem such that a Bayesian incentive compatible, interim individually rational and ex post efficient mechanism exists.

The key step in the proof is to choose $q_{0}$ such that if both agents are of their worst-off types, the gains from trade are zero. Note that in non-trivial situations this condition is violated for $q_{0}=0$, where the gains from trade are $a_{1}+a_{2}$ if the parties are of their worst-off types. If the trade decision is non-trivial, then the buyer's smallest possible valuation $a_{1}$ is smaller than the seller's largest possible cost, $-a_{2}$, so that $a_{1}+a_{2}<0$. However, using Lemma 2, one can show with an intermediate value argument that there always exists a $q_{0}$, such that the worst-off types satisfy $v_{1}^{0}+v_{2}^{0}=0$. Some technical work is then needed to show that the sum of the agents' expected utilities given that they are of their worst-off types is non-negative.

Proposition 3 is also related to Cramton, Gibbons, and Klemperer (1987). A significant difference is that here the distributions are not required to be

\footnotetext{
${ }^{12}$ See also Neeman (1999) for a related model that has been independently developed.
} 
identical, even the supports can be different. In the application presented in the next section it is important to allow different distributions, since there the distributions are determined endogenously. Moreover, Proposition 3 is related to McAfee (1991). However, there only ex ante budget balance is required (i.e., there is a third party acting as budget balancer), and the ex post efficient trade decision $q^{*}$ must be characterized by a first order condition, which here (and in Myerson and Satterthwaite, 1983) is not the case. $^{13}$

\section{An application to the hold-up problem}

The hold-up problem has received considerable attention in the contract theoretic literature in recent years. A hold-up problem occurs if prior to a trade decision, the gains from trade can be enhanced by relationship specific investments. As has been pointed out in the introduction, there are several recent papers that show for the case of observable valuations that the first best may not only be achieved by sophisticated contracts, but also by simple contracts when they are renegotiated in a certain way. It has been shown by Konakayama, Mitsui and Watanabe (1986), Rogerson (1992) and Hermalin and Katz (1993) that comprehensive contracts can even implement the first best if the parties' valuations are private information. Hence, it is an interesting question to ask whether in this case it is also possible to achieve the first best with simple unconditional contracts which are renegotiated.

Assume first that there are no investments to be made. From Proposition 3 it is known that the parties can write a simple contract that just specifies an

\footnotetext{
${ }^{13}$ See also McAfee and Reny (1992), who show that ex post efficiency may be achieved if the buyer's valuation and the seller's costs are correlated, provided that there is a third party acting as budget breaker.
} 
unconditional trade level $q_{0}$, such that negotiations starting after the buyer and the seller have learned their types can lead to ex post efficiency. One can think of these negotiations as if a mechanism were proposed by a third party that aims to achieve ex post efficiency. ${ }^{14}$ While some technical work is needed in order to make this precise, it is not difficult to see that under the assumption that renegotiation leads to ex post efficiency (when possible), also the right investment incentives are provided, given that a party's investment only influences his or her own type. ${ }^{15}$ Intuitively, the reason is that a party's ex ante expected utility from an ex post efficient mechanism is (up to a constant) equal to the total expected surplus, so that each party is residual claimant on the margin from his or her point of view.

To be precise, consider the following situation. A buyer and a seller write a simple contract at date 0 , that merely specifies an unconditional level of trade, $q_{0} \in[0,1]$. At date 1 , the buyer and the seller make unobservable relationship-specific investments $e_{1} \geq 0$ and $e_{2} \geq 0$, respectively. The buyer's valuation $v_{1}$ and the seller's costs $-v_{2}$ are determined by their investments and the state of the world, which is realized at date 2 . Let $v_{i}$ be distributed according to the continuous density function $\hat{f}_{i}\left(v_{i} \mid e_{i}\right)$, which is strictly positive on the interior of $\left[a_{i}, b_{i}\right]$, and let the corresponding distribution function be denoted by $\hat{F}_{i}\left(v_{i} \mid e_{i}\right)$. The realizations of the stochastically independent random variables $v_{1}$ and $v_{2}$ are private information of the buyer and the

\footnotetext{
${ }^{14}$ It has been pointed out by Tirole $(1992,1994)$ that renegotiation is a particular form of collusion, since renegotiation can be viewed as collusion among future incarnations of agents against their current incarnations. Renegotiation here is modelled in the same way as collusion under private information is now usually being modelled, namely by employing an uninformed third party as mechanism designer (see Laffont and Martimort, 1997 and 1998, and Laffont and Rochet, 1997).

${ }^{15}$ Hence, investments are 'selfish' in the sense of Che and Hausch (1999).
} 
seller, respectively. At date 3, the initial contract may be renegotiated. Finally, trade can occur and payments can be made at date 4 .

Let $C_{i}\left(e_{i}\right)$ denote party $i$ 's cost function for the investment. Let $q \in[0,1]$ denote the probability (or level) of trade and $t_{2} \equiv-t_{1}$ the (possibly negative) net payment of the buyer to the seller. The utilities of the buyer and the seller after date 4 are given by

$$
\begin{aligned}
& u^{B}=q v_{1}+t_{1}-C_{1}\left(e_{1}\right) \\
& u^{S}=q v_{2}+t_{2}-C_{2}\left(e_{2}\right) .
\end{aligned}
$$

At date 0 the parties want to design a contract which implements the ex post efficient trade decision

$$
q^{*}(v)= \begin{cases}1 & \text { if } v_{1} \geq-v_{2} \\ 0 & \text { otherwise }\end{cases}
$$

as well as the ex ante efficient investment levels:

Definition 4 The ex ante efficient investment levels $e_{1}^{*}$ and $e_{2}^{*}$ are given by

$$
e_{i}^{*} \in \arg \max _{e_{i}}\left(E\left[\left(v_{1}+v_{2}\right) q^{*}(v) \mid e_{i}, e_{-i}^{*}\right]-C_{i}\left(e_{i}\right)\right) .
$$

For simplicity it is assumed that the ex ante efficient investment levels $e_{1}^{*}$ and $e_{2}^{*}$ are uniquely determined. Let $F_{i}\left(v_{i}\right) \equiv \hat{F}_{i}\left(v_{i} \mid e_{i}^{*}\right)$ and $f_{i}\left(v_{i}\right) \equiv$ $\hat{f}_{i}\left(v_{i} \mid e_{i}^{*}\right), i=1,2$.

In order to model the renegotiation game at date 3 , it is assumed that a mediator who is interested in achieving ex post efficiency proposes a direct mechanism $[q(\tilde{v}), t(\tilde{v})]$. The parties can either accept or reject this mechanism. If at least one party does not accept the renegotiation mechanism, the original contract remains valid; i.e., the default decision $q_{0}$ is implemented. Otherwise the parties announce their valuations and then the decision and transfer payments are determined by the renegotiation mechanism. 
I say that "the first best can be achieved with a simple contract and renegotiation" if there exists a default decision $q_{0}$ and a mechanism $[q(v), t(v)]$ which yields the ex post efficient decision $q^{*}(v)$ and induces the parties to choose the ex ante efficient investment levels $e_{1}^{*}$ and $e_{2}^{*}$.

The following lemma says that in an incentive compatible and ex post efficient mechanism, agent $i$ 's interim expected utility equals the total expected surplus plus or minus a constant which does not depend on his or her type. ${ }^{16}$ In the lemma it is assumed that each agent believes that the other agent has invested efficiently, so that $E_{-i}$ is the expectation operator associated with the distribution function $F_{-i}$ and $T_{i}\left(\tilde{v}_{i}\right)$ is defined as in Section 2.

Lemma 3 A renegotiation mechanism $[q(v), t(v)]$ is Bayesian incentive compatible and ex post efficient if and only if $q(v)=q^{*}(v)$ and $\forall i, \forall v, \forall \tilde{v}_{i}$ :

$$
T_{i}\left(v_{i}\right)-T_{i}\left(\tilde{v}_{i}\right)=E_{-i}\left[v_{-i}\left(q^{*}(v)-q^{*}\left(\tilde{v}_{i}, v_{-i}\right)\right)\right]
$$

This lemma can now be used in order to show that indeed an ex post efficient and incentive compatible renegotiation mechanism induces the right investment incentives.

Lemma 4 Let $\left[q^{*}(v), t(v)\right]$ be a renegotiation mechanism such that (5) is satisfied. Then the agents are induced to choose the ex ante efficient investment levels $e_{1}^{*}$ and $e_{2}^{*}$.

Intuitively, in a Bayesian incentive compatible and ex post efficient mechanism, each agent is residual claimant from his or her point of view. Hence, it is in the interest of each agent not only to tell the truth, but also to invest efficiently. This is true since an agent's investment only influences his or her own type, and not the type of other agents (cf. Rogerson, 1992). It is now possible to state the following result.

\footnotetext{
${ }^{16}$ See D'Aspremont and Gérard-Varet (1979) and Arrow (1979).
} 
Proposition 4 The first best can be achieved with a simple contract and renegotiation.

Two remarks have to be made. First, the fact that there exists a bargaining game such that the first best is achieved does not guarantee that in real life contractual parties will actually always play this particular game. The mechanism design approach taken in this paper only allows to look for an upper bound on the achievable surplus. There is no obvious way how to model contract renegotiation. Even if there is no private information, there are several competing approaches. Some authors use an axiomatic approach such as the Nash bargaining solution, while others prefer a non-cooperative bargaining model. Some authors argue that the parties can design the renegotiation game, while others think it should be exogenously given. Of course, in the presence of private information, analogous considerations could be made. ${ }^{17}$

Second, it is not claimed that the renegotiation mechanism is in itself 'renegotiation-proof' with respect to further negotiations. Assume that a party refuses to participate in the renegotiation mechanism proposed by the third party. Then the original contract would remain valid. Since $q_{0} \in(0,1)$ is ex post inefficient with probability 1 , one could imagine that this would not be the end of the game. However, this is a general problem of models in which renegotiation is modelled as a non-cooperative game, even if there is no private information. For example, renegotiation is often modelled so that one of the two contractual parties can make a take-it-or-leave-it offer to the other party. ${ }^{18}$ However, the "or-leave-it" threat is usually inefficient. Hardly

\footnotetext{
${ }^{17}$ Cf. also Dewatripont and Maskin (1990) and the literature cited there.

${ }^{18}$ See Fudenberg and Tirole (1990) or Ma (1994). Hart (1995, p. 77) considers the case in which each party can make a take-it-or-leave-it offer with probability $\frac{1}{2}$, which corresponds to the Nash bargaining solution.
} 
anything may be implementable if no inefficient threats in the renegotiation game are allowed. ${ }^{19}$

\section{Conclusion}

In Section 2 it has been shown that the presence of private information does not necessarily imply that voluntary bargaining over a collective decision cannot yield an ex post efficient outcome. The impossibility results of the literature initiated by Myerson and Satterthwaite (1983) may be too pessimistic if the default decision is non-trivial. In Section 3 this result has been applied to the hold-up problem. It has been argued that a simple contract which is renegotiated may lead to the first best, even if the parties' valuations are private information. This is well in line with a large number of recent papers which have proved similar results for the case of observable valuations.

Notice that if the decision is whether or not to trade one unit of an indivisible good, then $0<q_{0}<1$ means that the original contract has to specify randomization. ${ }^{20}$ It is interesting to note that related results have been obtained for quite different reasons in hold-up models with observable valuations. In order to prove their well-known inefficiency result, Hart and Moore (1988) implicitly assume that no trade $\left(q_{0}=0\right)$ is the only possible default decision. In a modification of their model, Aghion, Dewatripont and Rey $(1990,1994)$ explicitly allow randomization $\left(0<q_{0}<1\right)$ as default

\footnotetext{
${ }^{19}$ Cf. Proposition 1 in Rubinstein and Wolinsky (1992).

${ }^{20}$ Using a simple model with uniform distributions and no investments, Schmitz (1998) discusses a coalition contract between two political parties in Germany which specifies randomization in case of disagreement.
} 
decision and show that then the first best can be achieved. ${ }^{21}$ While in these models an intermediate value of $q_{0}$ serves to adjust the threat point in a Nash bargaining game, in the present model an intermediate value of $q_{0}$ is advantageous because it relaxes the interim participation constraints (cf. Section 2). In any case, as has been pointed out by Edlin and Reichelstein (1996, p. 494), a contract to trade half a table might well be efficient, even though it is only efficient ex post to trade a whole table or nothing.

The paper suggests several interesting avenues for future research. First, Section 2 has illustrated that default decisions are relevant even if there are no investments. Indeed, it has been pointed out by Hart (1995) and Moore (1992) that the hold-up problem is only one vehicle for their theory of property rights. Given private information, one may analyze the effects of different ownership structures (control rights over $q$ ) and try to relate them to insights gained in models with investment decisions but observable valuations. Second, it has been assumed that agent $i$ 's investment only influences his or her own valuation $v_{i}$. In the case of observable valuations, Che and Hausch (1999) have recently analyzed the effects of 'cooperative investments'; i.e., investments which have direct external effects on the valuations of other agents. It would be interesting to analyze what happens if private information is introduced into their model. ${ }^{22}$ Finally, in this paper a mechanism design approach has been used in order to investigate what

${ }^{21}$ Analogously, Edlin and Reichelstein (1996) argue that the first best can be achieved in Rogerson's (1984) model. While Rogerson (1984) considered deterministic default decisions only, Edlin and Reichelstein (1996) allow the initial contract to specify trade with a certain probability.

${ }^{22}$ In a first attempt to address this question, Schmitz (2002) shows that in this case there is in general no hope to achieve the first best, even if comprehensive contracts can be written and renegotiation can be ruled out. 
could be the best possible outcome of contract renegotiation under private information. Of course, in real life there often is no benevolent mediator who proposes a renegotiation mechanism to the contractual parties. It is an open question for future research what happens if renegotiation is modelled by a generalization of the Nash bargaining solution for bargaining problems with incomplete information (see Myerson, 1984) or by exogenously given non-cooperative bargaining games. ${ }^{23}$

\footnotetext{
${ }^{23}$ See also Farrell and Gibbons (1995). Note, however, that their focus is on adverse selection (precontractual information at the ex ante stage) and not on hidden information (private information at the ex post bargaining stage).
} 


\section{Appendix}

\section{A1. Proof of Lemma 1.}

(i) "Only if": (1) implies

$$
\begin{aligned}
& U_{i}\left(v_{i}\right)=v_{i} Q_{i}\left(v_{i}\right)+T_{i}\left(v_{i}\right) \geq v_{i} Q_{i}\left(\tilde{v}_{i}\right)+T_{i}\left(\tilde{v}_{i}\right) \\
& U_{i}\left(\tilde{v}_{i}\right)=\tilde{v}_{i} Q_{i}\left(\tilde{v}_{i}\right)+T_{i}\left(\tilde{v}_{i}\right) \geq \tilde{v}_{i} Q_{i}\left(v_{i}\right)+T_{i}\left(v_{i}\right) .
\end{aligned}
$$

Hence, $\left(v_{i}-\tilde{v}_{i}\right) Q_{i}\left(v_{i}\right) \geq U_{i}\left(v_{i}\right)-U_{i}\left(\tilde{v}_{i}\right) \geq\left(v_{i}-\tilde{v}_{i}\right) Q_{i}\left(\tilde{v}_{i}\right)$, which implies $\left(v_{i}-\tilde{v}_{i}\right)\left(Q_{i}\left(v_{i}\right)-Q_{i}\left(\tilde{v}_{i}\right)\right) \geq 0$; i.e., $Q_{i}\left(v_{i}\right)$ is non-decreasing, and $U_{i}^{\prime}\left(v_{i}\right)=$ $Q_{i}\left(v_{i}\right)$ a.e., so that

$$
U_{i}\left(v_{i}\right)=U_{i}\left(\tilde{v}_{i}\right)+\int_{\tilde{v}_{i}}^{v_{i}} Q_{i}\left(\check{v}_{i}\right) d \check{v}_{i}
$$

(ii) "If": Using the condition of the lemma, the definition of $U_{i}\left(\tilde{v}_{i}\right)$, and partial integration one finds

$$
\begin{aligned}
& U_{i}\left(v_{i}\right)-v_{i} Q_{i}\left(\tilde{v}_{i}\right)-T_{i}\left(\tilde{v}_{i}\right) \\
= & U_{i}\left(\tilde{v}_{i}\right)+\int_{\tilde{v}_{i}}^{v_{i}} Q_{i}\left(\check{v}_{i}\right) d \check{v}_{i}-v_{i} Q_{i}\left(\tilde{v}_{i}\right)-T_{i}\left(\tilde{v}_{i}\right) \\
= & \left(\tilde{v}_{i}-v_{i}\right) Q_{i}\left(\tilde{v}_{i}\right)+\int_{\tilde{v}_{i}}^{v_{i}} Q_{i}\left(\check{v}_{i}\right) d \check{v}_{i} \\
= & v_{i}\left(Q_{i}\left(v_{i}\right)-Q_{i}\left(\tilde{v}_{i}\right)\right)-\int_{\tilde{v}_{i}}^{v_{i}} \check{v}_{i} Q_{i}^{\prime}\left(\check{v}_{i}\right) d \check{v}_{i} \\
= & \int_{\tilde{v}_{i}}^{v_{i}}\left(v_{i}-\check{v}_{i}\right) Q_{i}^{\prime}\left(\check{v}_{i}\right) d \check{v}_{i} \geq 0,
\end{aligned}
$$

where the inequality follows since $Q_{i}\left(v_{i}\right)$ is non-decreasing. Hence, (1) is satisfied.

\section{A2. Proof of Lemma 2.}

Note that interim individual rationality is satisfied whenever $U_{i}\left(v_{i}\right)-q_{0} v_{i}$ is non-negative for all $i$ and all $v_{i}$. According to Lemma 1, the first derivative of $U_{i}\left(v_{i}\right)-q_{0} v_{i}$ is given by $Q_{i}\left(v_{i}\right)-q_{0}$, which is non-decreasing in $v_{i}$. If 
the first derivative is always positive or always negative, the minimization of $U_{i}\left(v_{i}\right)-q_{0} v_{i}$ yields a corner solution, otherwise the minimum is characterized by the first-order condition $Q_{i}\left(v_{i}^{0}\right)=q_{0}$.

\section{A3. Proof of Proposition 1.}

(i) "Only if": Using Lemma 1 and partial integration, one can write agent $i$ 's ex ante expected utility as

$$
\begin{aligned}
E_{i}\left[U_{i}\left(v_{i}\right)\right] & =U_{i}\left(v_{i}^{0}\right)+E_{i}\left[\int_{v_{i}^{0}}^{v_{i}} Q_{i}\left(\check{v}_{i}\right) d \check{v}_{i}\right] \\
& =U_{i}\left(v_{i}^{0}\right)+\int_{a_{i}}^{b_{i}} \int_{v_{i}^{0}}^{v_{i}} Q_{i}\left(\check{v}_{i}\right) d \check{v}_{i} f_{i}\left(v_{i}\right) d v_{i} \\
& =U_{i}\left(v_{i}^{0}\right)+\int_{v_{i}^{0}}^{b_{i}} Q_{i}\left(\check{v}_{i}\right) d \check{v}_{i}-\int_{a_{i}}^{b_{i}} Q_{i}\left(v_{i}\right) \frac{F_{i}\left(v_{i}\right)}{f_{i}\left(v_{i}\right)} f_{i}\left(v_{i}\right) d v_{i} .
\end{aligned}
$$

Rearranging and using the definitions of $U_{i}\left(v_{i}\right)$, one finds

$$
\begin{aligned}
U_{i}\left(v_{i}^{0}\right) & =E_{i}\left[U_{i}\left(v_{i}\right)+\frac{F_{i}\left(v_{i}\right)}{f_{i}\left(v_{i}\right)} Q_{i}\left(v_{i}\right)\right]-\int_{v_{i}^{0}}^{b_{i}} Q_{i}\left(v_{i}\right) d v_{i} \\
& =E_{i}\left[\left(v_{i}+\frac{F_{i}\left(v_{i}\right)}{f_{i}\left(v_{i}\right)}\right) Q_{i}\left(v_{i}\right)+T_{i}\left(v_{i}\right)\right]-\int_{v_{i}^{0}}^{b_{i}} Q_{i}\left(v_{i}\right) d v_{i} .
\end{aligned}
$$

Summing over all $i$ and using $\sum_{i} E_{i}\left[T_{i}\left(v_{i}\right)\right]=\sum_{i} E\left[t_{i}(v)\right]=E\left[\sum_{i} t_{i}(v)\right]=0$, it follows that

$$
\begin{aligned}
\sum_{i=1}^{n} U_{i}\left(v_{i}^{0}\right)= & E_{i}\left[\sum_{i=1}^{n}\left(v_{i}+\frac{F_{i}\left(v_{i}\right)}{f_{i}\left(v_{i}\right)}\right) Q_{i}\left(v_{i}\right)\right]-\sum_{i=1}^{n} \int_{v_{i}^{0}}^{b_{i}} Q_{i}\left(v_{i}\right) d v_{i} \\
= & \sum_{i=1}^{n}\left(\int_{a_{i}}^{b_{i}}\left(v_{i}+\frac{F_{i}\left(v_{i}\right)}{f_{i}\left(v_{i}\right)}\right) Q_{i}\left(v_{i}\right) f_{i}\left(v_{i}\right) d v_{i}\right. \\
& \left.-\int_{v_{i}^{0}}^{b_{i}} Q_{i}\left(v_{i}\right) \frac{f_{i}\left(v_{i}\right)}{f_{i}\left(v_{i}\right)} d v_{i}\right) \\
= & \sum_{i=1}^{n}\left(\int_{v_{i}^{0}}^{b_{i}}\left(v_{i}-\frac{1-F_{i}\left(v_{i}\right)}{f_{i}\left(v_{i}\right)}\right) Q_{i}\left(v_{i}\right) f_{i}\left(v_{i}\right) d v_{i}\right. \\
& \left.+\int_{a_{i}}^{v_{i}^{0}}\left(v_{i}+\frac{F_{i}\left(v_{i}\right)}{f_{i}\left(v_{i}\right)}\right) Q_{i}\left(v_{i}\right) f_{i}\left(v_{i}\right) d v_{i}\right) .
\end{aligned}
$$


According to Lemma 2, interim individual rationality implies that this expression must not be smaller than $\sum_{i=1}^{n} q_{0} v_{i}^{0}$, which proves the first direction.

(ii) "If": The goal is to construct a transfer scheme $t(v)$ such that $[q(v)$, $t(v)]$ is a Bayesian incentive compatible and individually rational mechanism. Define

$$
\begin{aligned}
t_{i}(v)= & \frac{1}{n} \sum_{j=1}^{n}\left(\int_{a_{j}}^{b_{j}}\left(v_{j}+\frac{F_{j}\left(v_{j}\right)}{f_{j}\left(v_{j}\right)}\right) Q_{j}\left(v_{j}\right) f_{j}\left(v_{j}\right) d v_{j}\right. \\
& \left.-\int_{v_{j}^{0}}^{b_{j}} Q_{j}\left(v_{j}\right) d v_{j}-q_{0} v_{j}^{0}\right) \\
& -\frac{1}{n-1} \sum_{j \neq i}\left(\int_{a_{j}}^{b_{j}}\left(v_{j}+\frac{F_{j}\left(v_{j}\right)}{f_{j}\left(v_{j}\right)}\right) Q_{j}\left(v_{j}\right) f_{j}\left(v_{j}\right) d v_{j}\right. \\
& \left.-\int_{v_{j}}^{b_{j}} Q_{j}\left(\check{v}_{j}\right) d \check{v}_{j}-v_{j} Q_{j}\left(v_{j}\right)\right) \\
& +\int_{v_{i}^{0}}^{v_{i}} Q_{i}\left(\check{v}_{i}\right) d \check{v}_{i}-v_{i} Q_{i}\left(v_{i}\right)+q_{0} v_{i}^{0} .
\end{aligned}
$$

Note that $\sum_{i=1}^{n} t_{i}(v)=0$ and

$$
E_{-i}\left[t_{i}\left(v_{i}, v_{-i}\right)-t_{i}\left(\tilde{v}_{i}, v_{-i}\right)\right]=\int_{\tilde{v}_{i}}^{v_{i}} Q_{i}\left(\check{v}_{i}\right) d \check{v}_{i}-v_{i} Q_{i}\left(v_{i}\right)+\tilde{v}_{i} Q_{i}\left(\tilde{v}_{i}\right)
$$

Thus,

$$
U_{i}\left(v_{i}\right)-U_{i}\left(\tilde{v}_{i}\right)=\int_{\tilde{v}_{i}}^{v_{i}} Q_{i}\left(\check{v}_{i}\right) d \check{v}_{i}
$$

so that Bayesian incentive compatibility is satisfied by Lemma 1. Finally, notice that

$$
\begin{aligned}
& E_{-i}\left[\sum _ { j \neq i } \left(\int_{a_{j}}^{b_{j}}\left(v_{j}+\frac{F_{j}\left(v_{j}\right)}{f_{j}\left(v_{j}\right)}\right) Q_{j}\left(v_{j}\right) f_{j}\left(v_{j}\right) d v_{j}\right.\right. \\
& \left.\left.-\int_{v_{j}}^{b_{j}} Q_{j}\left(\check{v}_{j}\right) d \check{v}_{j}-v_{j} Q_{j}\left(v_{j}\right)\right)\right] \\
= & \sum_{j \neq i}\left(\int_{a_{j}}^{b_{j}}\left(\frac{F_{j}\left(v_{j}\right)}{f_{j}\left(v_{j}\right)}\right) Q_{j}\left(v_{j}\right) f_{j}\left(v_{j}\right) d v_{j}-\int_{a_{j}}^{b_{j}} \int_{v_{j}}^{b_{j}} Q_{j}\left(\check{v}_{j}\right) d \check{v}_{j} f_{j}\left(v_{j}\right) d v_{j}\right) \\
= & 0,
\end{aligned}
$$


where the last line follows from partial integration. Hence,

$$
\begin{aligned}
& U_{i}\left(v_{i}^{0}\right)-q_{0} v_{i}^{0}=v_{i}^{0} Q_{i}\left(v_{i}^{0}\right)+E_{-i}\left[t_{i}\left(v_{i}^{0}, v_{-i}\right)\right]-q_{0} v_{i}^{0} \\
& =\frac{1}{n} \sum_{j=1}^{n}\left(\int_{a_{j}}^{b_{j}}\left(v_{j}+\frac{F_{j}\left(v_{j}\right)}{f_{j}\left(v_{j}\right)}\right) Q_{j}\left(v_{j}\right) f_{j}\left(v_{j}\right) d v_{j}\right. \\
& \left.\quad-\int_{v_{j}^{0}}^{b_{j}} Q_{j}\left(v_{j}\right) d v_{j}-q_{0} v_{j}^{0}\right) \\
& =\frac{1}{n} \sum_{j=1}^{n}\left(\int_{v_{j}^{0}}^{b_{j}}\left(v_{j}-\frac{1-F_{j}\left(v_{j}\right)}{f_{j}\left(v_{j}\right)}\right) Q_{j}\left(v_{j}\right) f_{j}\left(v_{j}\right) d v_{j}\right. \\
& \left.+\int_{a_{j}}^{v_{j}^{0}}\left(v_{j}+\frac{F_{j}\left(v_{j}\right)}{f_{j}\left(v_{j}\right)}\right) Q_{j}\left(v_{j}\right) f_{j}\left(v_{j}\right) d v_{j}-q_{0} v_{j}^{0}\right),
\end{aligned}
$$

which by assumption is non-negative, yielding interim individual rationality. ${ }^{24}$

\section{A4. Proof of Proposition 2.}

It is obvious that ex post efficiency can be achieved if trade is always efficient $\left(a=a_{i} \geq 0\right)$ or if trade is never efficient $\left(b=b_{i} \leq 0\right)$. Consider hence the non-trivial case $a<0<b$. Let $Q_{i}\left(v_{i}\right)=E_{-i}\left(q^{*}(v)\right)$ and note that $Q_{i}\left(v_{i}\right)=\operatorname{Pr}\left\{\sum_{j \neq i} v_{j}>-v_{i}\right\}$. Notice that $Q_{i}(a)<q_{0}<Q_{i}(b)$, such that by Lemma 2 the worst-off type $v_{i}^{0}$ is implicitly characterized by $q_{0}=Q_{i}\left(v_{i}^{0}\right)$; i.e., $\operatorname{Pr}\left\{\sum_{j \neq i} v_{j}>0\right\}=\operatorname{Pr}\left\{\sum_{j \neq i} v_{j}>-v_{i}^{0}\right\}$. Thus, the worst-off types are given by $v_{i}^{0}=0 \forall i$. Using partial integration, the left hand side of (3) can be

${ }^{24}$ Note that the special case of Proposition 1 which refers only to the ex post efficient decision rule could alternatively be derived following the approach of Makowski and Mezzetti (1994) and Williams (1994). 
written as

$$
\begin{gathered}
\sum_{i=1}^{n}\left(\int_{a}^{0}\left(v_{i}+\frac{F\left(v_{i}\right)}{f\left(v_{i}\right)}\right) Q_{i}\left(v_{i}\right) f\left(v_{i}\right) d v_{i}\right. \\
\left.+\int_{0}^{b}\left(v_{i}-\frac{1-F\left(v_{i}\right)}{f\left(v_{i}\right)}\right) Q_{i}\left(v_{i}\right) f\left(v_{i}\right) d v_{i}\right) \\
=\sum_{i=1}^{n}\left(\int_{a}^{0}\left(v_{i} f\left(v_{i}\right)+F\left(v_{i}\right)\right) Q_{i}\left(v_{i}\right) d v_{i}\right. \\
\left.+\int_{0}^{b}\left(v_{i} f\left(v_{i}\right)-\left(1-F\left(v_{i}\right)\right)\right) Q_{i}\left(v_{i}\right) d v_{i}\right) \\
=\sum_{i=1}^{n}\left(-\int_{a}^{0} v_{i} F\left(v_{i}\right) Q_{i}^{\prime}\left(v_{i}\right) d v_{i}+\int_{0}^{b}\left(v_{i}\left(1-F\left(v_{i}\right)\right)\right) Q_{i}^{\prime}\left(v_{i}\right) d v_{i}\right) .
\end{gathered}
$$

It is straightforward to verify that this sum is not smaller than $\sum_{i=1}^{n} q_{0} v_{i}^{0}=0$, since $Q_{i}\left(v_{i}\right)$ is non-decreasing and $a<0<b$.

\section{A5. Proof of Proposition 3.}

Consider the case $a_{1}+a_{2}<0$ and $b_{1}+b_{2}>0$ (otherwise it is obvious that the first best can be achieved). Note that $F_{1}\left(v_{1}\right)$ is strictly increasing for $v_{1} \in\left[a_{1}, b_{1}\right]$ with $F_{1}\left(a_{1}\right)=0$ and $F_{1}\left(b_{1}\right)=1$, and that $F_{2}\left(-v_{1}\right)$ is strictly decreasing for $v_{1} \in\left[-b_{2},-a_{2}\right]$ with $F_{2}\left(b_{2}\right)=1$ and $F_{2}\left(a_{2}\right)=0$. Since $a_{1}<-a_{2}$ and $b_{1}>-b_{2}$, a simple intermediate value argument shows that a unique $\hat{v}_{1} \in\left(a_{1}, b_{1}\right) \cap\left(-b_{2},-a_{2}\right)$ exists such that $F_{1}\left(\hat{v}_{1}\right)=F_{2}\left(-\hat{v}_{1}\right)$.

Let $q_{0}=1-F_{1}\left(\hat{v}_{1}\right)$, which implies that $0<q_{0}<1$. Notice that $Q_{i}\left(v_{i}\right)=$ $E_{-i}\left[q^{*}(v) \mid e_{-i}^{*}\right]=1-F_{-i}\left(-v_{i}\right)$. It follows from Lemma 2 that $v_{1}^{0}=-v_{2}^{0}=\hat{v}_{1}$. It will now be shown that there exists an ex post efficient, Bayesian incentive compatible mechanism which is interim individually rational given the default decision $q_{0}$. Referring to Proposition 1 , it has to be shown that the following 
expression is non-negative:

$$
\begin{aligned}
& \sum_{i=1}^{2}\left(\int_{a_{i}}^{v_{i}^{0}}\left(v_{i}+\frac{F_{i}\left(v_{i}\right)}{f_{i}\left(v_{i}\right)}\right) Q_{i}\left(v_{i}\right) f_{i}\left(v_{i}\right) d v_{i}\right. \\
& \left.+\int_{v_{i}^{0}}^{b_{i}}\left(v_{i}-\frac{1-F_{i}\left(v_{i}\right)}{f_{i}\left(v_{i}\right)}\right) Q_{i}\left(v_{i}\right) f_{i}\left(v_{i}\right) d v_{i}\right)-\sum_{i=1}^{2} q_{0} v_{i}^{0} \\
& =\sum_{i=1}^{2}\left(\int_{a_{i}}^{v_{i}^{0}}\left(v_{i} f_{i}\left(v_{i}\right)+F_{i}\left(v_{i}\right)\right)\left(1-F_{-i}\left(-v_{i}\right)\right) d v_{i}\right. \\
& \left.+\int_{v_{i}^{0}}^{b_{i}}\left(v_{i} f_{i}\left(v_{i}\right)-\left(1-F_{i}\left(v_{i}\right)\right)\right)\left(1-F_{-i}\left(-v_{i}\right)\right) d v_{i}\right) \\
& =\sum_{i=1}^{2}\left(v_{i}^{0} F_{i}\left(v_{i}^{0}\right)\left(1-F_{-i}\left(-v_{i}^{0}\right)\right)-\int_{a_{i}}^{v_{i}^{0}} v_{i} F_{i}\left(v_{i}\right) f_{-i}\left(-v_{i}\right) d v_{i}\right. \\
& \left.+v_{i}^{0}\left(1-F_{i}\left(v_{i}^{0}\right)\right)\left(1-F_{-i}\left(-v_{i}^{0}\right)\right)+\int_{v_{i}^{0}}^{b_{i}}\left(v_{i}\left(1-F_{i}\left(v_{i}\right)\right)\right) f_{-i}\left(-v_{i}\right) d v_{i}\right) \\
& =\sum_{i=1}^{2}\left(-\int_{a_{i}}^{v_{i}^{0}} v_{i} F_{i}\left(v_{i}\right) f_{-i}\left(-v_{i}\right) d v_{i}+\int_{v_{i}^{0}}^{b_{i}}\left(v_{i}\left(1-F_{i}\left(v_{i}\right)\right)\right) f_{-i}\left(-v_{i}\right) d v_{i}\right) \\
& =\sum_{i=1}^{2}\left(-\int_{a_{i}}^{b_{i}} v_{i} F_{i}\left(v_{i}\right) f_{-i}\left(-v_{i}\right) d v_{i}+\int_{v_{i}^{0}}^{b_{i}} v_{i} f_{-i}\left(-v_{i}\right) d v_{i}\right) \\
& =\sum_{i=1}^{2}\left(-\int_{\max \left\{a_{i},-b_{-i}\right\}}^{\min \left\{b_{i},-a_{-i}\right\}} v_{i} F_{i}\left(v_{i}\right) f_{-i}\left(-v_{i}\right) d v_{i}+\int_{v_{i}^{0}}^{b_{i}} v_{i} f_{-i}\left(-v_{i}\right) d v_{i}\right) \\
& =-\int_{\max \left\{a_{1},-b_{2}\right\}}^{\min \left\{b_{1},-a_{2}\right\}} v F_{1}(v) f_{2}(-v) d v-\int_{\max \left\{a_{2},-b_{1}\right\}}^{\min \left\{b_{2},-a_{1}\right\}} v F_{2}(v) f_{1}(-v) d v \\
& +\sum_{i=1}^{2} \int_{v_{i}^{0}}^{b_{i}} v_{i} f_{-i}\left(-v_{i}\right) d v_{i} \\
& =-\int_{\max \left\{a_{1},-b_{2}\right\}}^{\min \left\{b_{1},-a_{2}\right\}} v F_{1}(v) f_{2}(-v) d v-\int_{\min \left\{b_{1},-a_{2}\right\}}^{\max \left\{a_{1},-b_{2}\right\}} v F_{2}(-v) f_{1}(v) d v \\
& +\sum_{i=1}^{2} \int_{v_{i}^{0}}^{b_{i}} v_{i} f_{-i}\left(-v_{i}\right) d v_{i} \\
& =\int_{\min \left\{b_{1},-a_{2}\right\}}^{\max \left\{a_{1},-b_{2}\right\}} v\left(F_{1}(v) f_{2}(-v)-F_{2}(-v) f_{1}(v)\right) d v+\sum_{i=1}^{2} \int_{v_{i}^{0}}^{b_{i}} v_{i} f_{-i}\left(-v_{i}\right) d v_{i}
\end{aligned}
$$




$$
\begin{aligned}
= & -\max \left\{a_{1},-b_{2}\right\} F_{1}\left(\max \left\{a_{1},-b_{2}\right\}\right)+\min \left\{b_{1},-a_{2}\right\} F_{2}\left(-\min \left\{b_{1},-a_{2}\right\}\right) \\
& +\int_{\min \left\{b_{1},-a_{2}\right\}}^{\max \left\{a_{1},-b_{2}\right\}} F_{1}(v) F_{2}(-v) d v-b_{1} F_{2}\left(-b_{1}\right)+v_{1}^{0} F_{2}\left(-v_{1}^{0}\right)+\int_{v_{1}^{0}}^{b_{1}} F_{2}(-v) d v \\
& -b_{2} F_{1}\left(-b_{2}\right)+v_{2}^{0} F_{1}\left(-v_{2}^{0}\right)+\int_{v_{2}^{0}}^{b_{2}} F_{1}(-v) d v \\
= & \int_{\min \left\{b_{1},-a_{2}\right\}}^{\max \left\{a_{1},-b_{2}\right\}} F_{1}(v) F_{2}(-v) d v+\int_{v_{1}^{0}}^{b_{1}} F_{2}(-v) d v+\int_{-v_{1}^{0}}^{b_{2}} F_{1}(-v) d v \\
= & -\int_{\max \left\{a_{1},-b_{2}\right\}}^{\min \left\{b_{1},-a_{2}\right\}} F_{1}(v) F_{2}(-v) d v+\int_{v_{1}^{0}}^{b_{1}} F_{2}(-v) d v+\int_{-b_{2}}^{v_{1}^{0}} F_{1}(v) d v \\
= & \int_{\max \left\{a_{1},-b_{2}\right\}}^{v_{1}^{0}} F_{1}(v)\left(1-F_{2}(-v)\right) d v+\int_{v_{1}^{0}}^{\min \left\{b_{1},-a_{2}\right\}} F_{2}(-v)\left(1-F_{1}(v)\right) d v \\
& +\int_{-b_{2}}^{\max \left\{a_{1},-b_{2}\right\}} F_{1}(v) d v+\int_{\min \left\{b_{1},-a_{2}\right\}}^{b_{1}} F_{2}(-v) d v \geq 0
\end{aligned}
$$

The inequality holds since $v_{1}^{0} \in\left(a_{1}, b_{1}\right) \cap\left(-b_{2},-a_{2}\right)$. Hence, the ex post efficient decision rule is implementable.

\section{A6. Proof of Lemma 3.}

(i) "If": It has to be shown that $\forall v_{i}, \tilde{v}_{i}$ :

$$
U_{i}\left(v_{i}\right)=v_{i} Q_{i}\left(v_{i}\right)+T_{i}\left(v_{i}\right) \geq v_{i} Q_{i}\left(\tilde{v}_{i}\right)+T_{i}\left(\tilde{v}_{i}\right)
$$

where $Q_{i}\left(\tilde{v}_{i}\right)=E_{-i}\left[q^{*}\left(\tilde{v}_{i}, v_{-i}\right)\right]$. Equation (5) implies

$$
\begin{aligned}
& U_{i}\left(v_{i}\right)-\left(v_{i} Q_{i}\left(\tilde{v}_{i}\right)+T_{i}\left(\tilde{v}_{i}\right)\right) \\
= & v_{i}\left(Q_{i}\left(v_{i}\right)-Q_{i}\left(\tilde{v}_{i}\right)\right)+E_{-i}\left[v_{-i}\left(q^{*}\left(v_{i}, v_{-i}\right)-q^{*}\left(\tilde{v}_{i}, v_{-i}\right)\right)\right] \\
= & E_{-i}\left[\left(v_{i}+v_{-i}\right)\left(q^{*}\left(v_{i}, v_{-i}\right)-q^{*}\left(\tilde{v}_{i}, v_{-i}\right)\right)\right] \geq 0 .
\end{aligned}
$$

(ii) "Only if": It has been shown in Lemma 1 that in every Bayesian incentive compatible mechanism $U_{i}\left(v_{i}\right)-U_{i}\left(\tilde{v}_{i}\right)$ and hence $T_{i}\left(v_{i}\right)-T_{i}\left(\tilde{v}_{i}\right)$ is uniquely determined by the decision rule. Since $\left[q^{*}(v), t(v)\right]$ with $T_{i}\left(v_{i}\right)-$ $T_{i}\left(\tilde{v}_{i}\right)$ determined by (5) is Bayesian incentive compatible, this implies that 
every Bayesian incentive compatible and ex post efficient mechanism must satisfy (5).

\section{A7. Proof of Lemma 4.}

Suppose that agent $i$ believes that agent $-i$ has invested efficiently and tells the truth. It is already known from Lemma 3 that it is rational for agent $i$ to also tell the truth. The ex ante expected utility of agent $i$ provided that he or she invests $e_{i}$ thus reads

$$
\begin{aligned}
E_{i}\left[U_{i}\left(v_{i}\right) \mid e_{i}\right]= & E_{i}\left[v_{i} Q_{i}\left(v_{i}\right)+T_{i}\left(v_{i}\right) \mid e_{i}\right] \\
= & E_{i}\left[E_{-i}\left[\left(v_{i}+v_{-i}\right) q^{*}(v) \mid e_{-i}^{*}\right] \mid e_{i}\right] \\
& +T_{i}\left(\tilde{v}_{i}\right)-E_{-i}\left[v_{-i} q^{*}\left(\tilde{v}_{i}, v_{-i}\right) \mid e_{-i}^{*}\right] .
\end{aligned}
$$

The last two terms do not depend on $e_{i}$. Hence, agent $i$ chooses $e_{i}$ in order to maximize

$$
E\left[\left(v_{i}+v_{-i}\right) q^{*}(v) \mid e_{i}, e_{-i}^{*}\right]-C_{i}\left(e_{i}\right),
$$

so that he or she will invest efficiently.

\section{A8. Proof of Proposition 4.}

This follows immediately from Proposition 3 and Lemma 4. 


\section{References}

Aghion, P., Dewatripont, M., Rey, P., 1990. On renegotiation design. European Economic Review 34, 322-329.

Aghion, P., Dewatripont, M., Rey, P., 1994. Renegotiation design with unverifiable information. Econometrica 62, 257-282.

Arrow, K.J., 1979. The property rights doctrine and demand revelation under incomplete information. In: Boskin, M.J. (Ed.), Economics and Human Welfare - Essays in Honor of Tibor Scitovsky. Academic Press, New York, pp. 23-39.

Bulow, J., Roberts, J., 1989. The simple economics of optimal auctions. Journal of Political Economy 97, 1060-1090.

Che, Y.-K., Hausch, D.B., 1999. Cooperative investments and the value of contracting. American Economic Review 89, 125-147.

Chung, T.-Y., 1991. Incomplete contracts, specific investments, and risk sharing. Review of Economic Studies 58, 1031-1042.

Cramton, P., Gibbons, R., Klemperer, P., 1987. Dissolving a partnership efficiently. Econometrica 55, 615-632.

D’Aspremont, C., Gérard-Varet, L.-A., 1979. Incentives and incomplete information. Journal of Public Economics 11, 25-45.

Dewatripont, M., Maskin, E., 1990. Contract renegotiation in models of asymmetric information. European Economic Review 34, 311-321. 
Edlin, A.S., 1996. Cadillac contracts and up-front payments: Efficient investment under expectation damages. Journal of Law, Economics, and Organization 12, 98-118.

Edlin, A.S., Reichelstein, S., 1996. Holdups, standard breach remedies and optimal investment. American Economic Review 86, 478-501.

Farrell, J., Gibbons, R., 1995. Cheap talk about specific investments. Journal of Law, Economics, and Organization 11, 313-334.

Fudenberg, D., Tirole, J., 1990. Moral hazard and renegotiation in agency contracts. Econometrica 58, 1279-1319.

Güth, W., Hellwig, M., 1986. The private supply of a public good. Journal of Economics, Suppl. 5, 121-159.

Hart, O.D., 1995. Firms, Contracts and Financial Structure. Clarendon Press, Oxford.

Hart, O., Holmström, B., 1987. The theory of contracts. In: Bewley, T. (Ed.), Advances in Economic Theory. Cambridge University Press, Cambridge, pp. 71-155.

Hart, O., Moore, J., 1988. Incomplete contracts and renegotiation. Econometrica $56,755-785$.

Hermalin, B., Katz, M., 1993. Judicial modifications of contracts between sophisticated parties: A more complete view of incomplete contracts and their breach. Journal of Law, Economics, and Organization 9, 230-255.

Huberman, G., Kahn, C., 1988. Limited contract enforcement and strategic renegotiation. American Economic Review 78, 471-484. 
Klibanoff, P., Morduch, J., 1995. Decentralization, externalities, and efficiency. Review of Economic Studies 62, 223-247.

Konakayama, A., Mitsui, T., Watanabe, S., 1986. Efficient contracting with reliance and a damage measure. Rand Journal of Economics 17, 450-457.

Laffont, J.-J., Martimort, D., 1997. Collusion under asymmetric information. Econometrica 65, 875-911.

Laffont, J.-J., Martimort, D., 1998. Collusion and delegation. Rand Journal of Economics 29, 280-305.

Laffont, J.-J., Rochet, J.-C., 1997. Collusion in organizations. Scandinavian Journal of Economics 99, 485-495.

Lewis, T., Sappington, D., 1989. Countervailing incentives in agency problems. Journal of Economic Theory 49, 294-313.

Ma, C.-T. A., 1994. Renegotiation and optimality in agency contracts. Review of Economic Studies 61, 109-129.

Maggi, G., Rodríguez-Clare, A., 1995. On countervailing incentives. Journal of Economic Theory 66, 238-263.

Mailath, G., Postlewaite, A., 1990. Asymmetric information bargaining problems with many agents. Review of Economic Studies 57, 351-367.

Makowski, L., Mezzetti, C., 1994. Bayesian and weakly robust first best mechanisms: Characterizations. Journal of Economic Theory 64, 500519.

McAfee, R.P., 1991. Efficient allocation with continuous quantities. Journal of Economic Theory 53, 51-74. 
McAfee, R.P., Reny, P., 1992. Correlated information and mechanism design. Econometrica 60, 395-421.

Moore, J., 1992. The firm as a collection of assets. European Economic Review 36, 493-507.

Myerson, R.B., 1982. Optimal coordination mechanisms in generalized principal-agent problems. Journal of Mathematical Economics 10, 6781.

Myerson, R.B., 1984. Two-person bargaining problems with incomplete information. Econometrica 52, 461-487.

Myerson, R.B., Satterthwaite, M.A., 1983. Efficient mechanisms for bilateral trading. Journal of Economic Theory 29, 265-281.

Neeman, Z., 1999. Property rights and efficiency of voluntary bargaining under asymmetric information. Review of Economic Studies 66, 679691.

Nöldeke, G., Schmidt, K.M., 1995. Option contracts and renegotiation: A solution to the hold-up problem. Rand Journal of Economics 26, 163-179.

Nöldeke, G., Schmidt, K.M., 1998. Sequential investments and options to own. Rand Journal of Economics 29, 633-653.

Rob, R., 1989. Pollution claim settlements under private information. Journal of Economic Theory 47, 307-333.

Rogerson, W., 1984. Efficient reliance and damage measure for breach of contract. Rand Journal of Economics 15, 39-53. 
Rogerson, W., 1992. Contractual solutions to the hold-up problem. Review of Economic Studies 59, 774-794.

Rubinstein, A., Wolinsky, A., 1992. Renegotiation-proof implementation and time preferences. American Economic Review 82, 600-614.

Schmitz, P.W., 1998. Randomization in coalition contracts. Public Choice $94,341-353$.

Schmitz, P.W., 2002. On the interplay of hidden action and hidden information in simple bilateral trading problems. Journal of Economic Theory $103,444-460$.

Tirole, J., 1992. Collusion and the theory of organizations. In: Laffont, J.J. (Ed.), Advances in Economic Theory, Vol. 2. Cambridge University Press, Cambridge, pp. 151-206.

Tirole, J., 1999. Incomplete contracts: Where do we stand? Econometrica $67,741-781$.

Williams, S.R., 1999. A characterization of efficient, Bayesian incentive compatible mechanisms. Economic Theory 14, 155-180. 